\title{
MANAGEMENT OF IMPERFORATE ANUS WITH RECTO-URETHRAL FISTULA*
}

\author{
BY \\ INGRID NICOLAI and FRITZ REHBEIN \\ From the Surgical Department of the Children's Hospital, Bremen
}

This paper is concerned with cases of imperforate anus with recto-urethral fistula in males and some cases with high recto-vaginal fistula in females, all being cases of the type III described by Ladd and Gross (1934) or the high level imperforate anus described by Denis Browne. These cases still present difficult problems (Browne, 1955; Forshall, 1957; Brayton and Norris, 1958; Gross, 1959).

Decisive advances in the management of this anomaly started with the one-stage abdominoperineal pull-through procedure, first suggested by Macleod (1880), first published in 1948 by Rhoads, Pipes and Randall and independently carried out by Norris, Brophy and Brayton (1949) since 1943.

Although this method enables the surgeon to free the blind-ending rectum very close to the rectal wall, this procedure may lead to injury of the delicate nerve junctions in the true pelvis and endanger the blood supply of the neighbouring organs, especially, if as in most cases, the lowest part of the rectal pouch descends distal to the fistula (Brayton and Norris, 1958; Rehbein, 1959), is distended as in newborns, is filled by meconium and has a thin wall (Potts, Riker and DeBoer, 1954; Browne, 1955). From the recent studies of Scott and Swenson (1959) we know that in ano-rectal malformations the nerve fibres in the true pelvis are present, but take a slightly different course. Their preservation may improve post-operative rectal control; damage to them may destroy all hope of continence, which can usually follow if the pubo-rectalis sling is anatomically well sited and functions well (Snyder, 1961).

From experience gained in rectal surgery in adults it is probable that damage to the nerve supply in the true pelvis may lead to disorders of bladder function and sexual potency (Bacon and Ross, 1954; Bruch, 1955; Stelzner, 1957), and Brayton and Norris (1958) state that the widespread use of the abdomino-perineal operation for imper-

\footnotetext{
* A paper read at a meeting of the British Association of Paediatric Surgeons in London, September 1962.
}

forate anus is too recent for a satisfactory answer to these two points to be known.

For this purpose Babcock (1947) and Bacon (1949) inaugurated a new technical procedure for carcinoma of the rectum. They left the rectum distal to the carcinoma untouched in its pelvic connexions, removing only the mucous membrane. This step was followed by a pull-through of the upper colon through the remaining rectum down to the anus. This abdomino-transanal operation with intrarectal pull-through is also used for polyposis (Ravitch, 1948; Ravitch and Handelsman, 1951; Devine and Webb, 1951).

In 1958 we attempted to transfer these ideas to high-level imperforate anus with recto-urethral fistula, and found the following procedure useful.

\section{Method}

After laparotomy the recto-sigmoid junction is freed close to the wall for about $1 \mathrm{~cm}$. of length only, the upper rectum is opened, cleaned and cut across. The proximal stump is temporarily closed; then tension sutures are placed around the lumen. Then starting at the edge, the mucous membrane of the rectal pouch is carefully removed. The mucous membrane is held by tension sutures which facilitate mobilization in the right layer. We found that removal of the mucous membrane was easier in newborns, but was possible also in older infants and children. After complete mobilization the mucous membrane is cut off at the level of the fistula. Next, the right index finger is introduced into the rectal pouch and the left one into the anal dimple. Bringing both fingers together as close as possible one can easily feel the deepest point of the pouch as well as the middle of the sphincteric muscles. At the perineum an oval excision of skin is made, and with the finger acting as a constant guide, forceps are introduced into the pouch. This artificial channel is carefully widened and the sigmoid colon, which was closed temporarily, is pulled through the remaining pouch, care being taken to avoid stretching. After reopening, the sigmoid colon is fixed around the skin excision.

It is very important to ensure that the blood supply is in no way jeopardized and to make sure that there is no tension. 

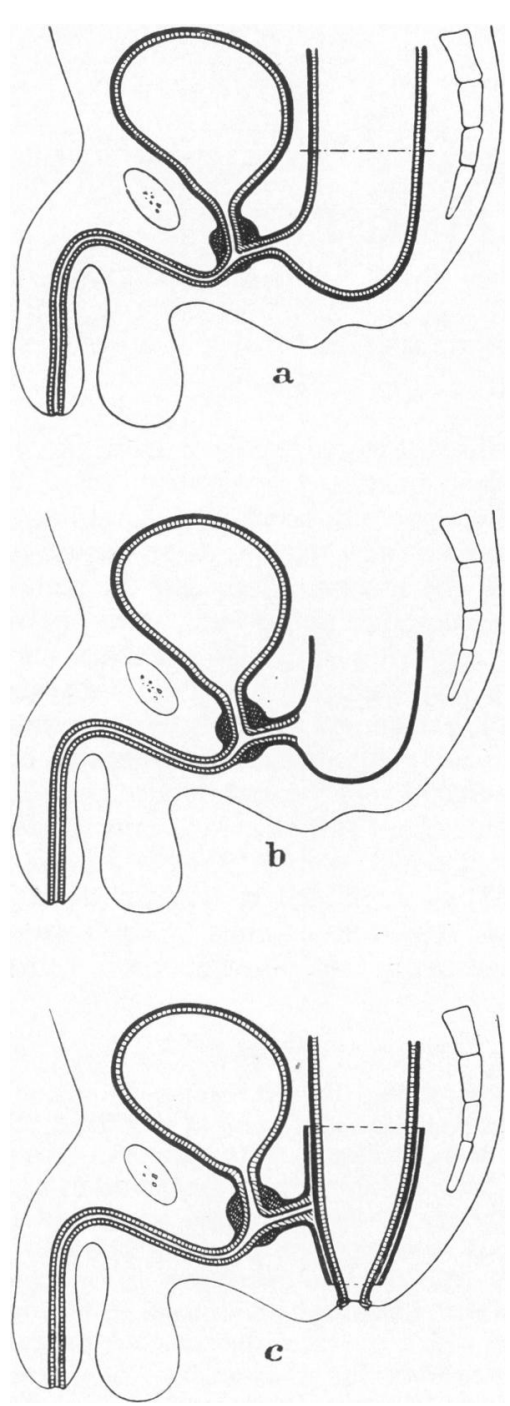

Figure.-Drawing of the operative technique. (a) Cut through the upper rectum; (b) the mucous membrane of the rectal pouch is completely removed; (c) pull-through of the sigmoid colon and fixation around the newly-built anus.

The Figure demonstrates the technique: the interrupted line in a indicates the cut across the upper rectum. The pouch descends distal to the fistula. At $\mathbf{b}$ the mucous membrane is completely removed and cut off at the level of the fistula; c shows the position at the end of the operation with the sigmoid colon pulled through the remaining pouch and fixed around the newly-built anus.

It is not necessary to close the fistula, because the wall of the sigmoid colon fits tightly over it.

\section{Results}

In 1959 we gave a preliminary report based upon five cases (Rehbein, 1959). Recently Romualdi (1960, 1961), Hartl (1960) and Hecker (1961) reported good results with this or a slightly modified method.

So far we have operated on 26 children in this way: 18 boys with imperforate anus and rectourethral fistula, seven girls with imperforate anus and high recto-vaginal fistula and one girl with ano-rectal stenosis and large recto-vaginal fistula, where a direct closure of the fistula was impossible. In this case we altered the method by removing the mucous membrane from the anus and rectum as high up as could be reached from the anus, and then worked downwards from the abdomen in the usual way. Before operation the stenosis was dilated by bouginage therapy. Seven months after operation the girl, now 2 years of age, has normal bowel evacuations two or three times daily without any soiling.

It is not possible from the relatively small numbers of cases and the short interval since operation to make definite statements about the functional results, but we can comment upon our experiences.

Four children died; of the 21 living cases we learned from investigations or questionnaires sent to the parents that 15 children developed rectal sensation and had daily bowel evacuations without or with occasional soiling. It is impossible to say more, because most of the children are still in the first years of life and so are normally not fully trained in bowel habits; some are rather late, because they had colostomy for varying lengths of time.

In the beginning we would not have risked performing this type of pull-through procedure without colostomy. Later on we learned that this precaution was not necessary. Nevertheless, our results in newborn infants are not good, since there of the four deaths were in this age-group. We agree with Forshall (1957), Potts et al. (1954), Brayton and Norris (1958) and Snyder (1961), that an operation should be performed at once if the general condition of the baby permits. Colostomy with delay of definite operation should be left for special cases only.

Constipation as mentioned by Scott and Swenson (1959) and Potts (1959) was not observed. It seems to be avoidable if the anus is regularly dilated for several months from the time the wound heals.

Because the intrarectal pull-through operation enables the surgeon to preserve the nerve and blood supply in the true pelvis as far as possible and to avoid additional operative damage (Scott and 
Swenson, 1959; Brayton and Norris, 1958; Snyder, 1961) we hope that there will be an improvement in post-operative results in this serious malformation.

\section{Summary}

The main problem in the surgical repair of imperforate anus with recto-urethral fistula lies in the difficulty in preserving the nerve and blood supply in the true pelvis during the mobilization of the blind-ending rectum for the pull-through procedure. In order to operate as carefully as possible, we chose a method quite similar to the abdomino-transanal operation with intrarectal pull-through inaugurated by Babcock and Bacon for carcinoma of the rectum. This method is also in use for polyposis of the rectum.

The main point of the technique is not to isolate the whole rectal pouch, but only to remove its mucous membrane after cutting across the upper rectum. The sigmoid colon is then pulled through the remaining pouch, consisting only of the muscular and serosal layer. The mucous membrane of the fistula may remain, because the fistula is firmly closed by the sigmoid wall, which lies closely over the fistula.

Since 1958 we have operated on 26 children in this way: 18 boys and seven girls with high level imperforate anus and fistula and one girl with anorectal stenosis and recto-vaginal fistula. The time lapse since operation is too short to make definite statements on the functional results. Up to now 15 children have developed rectal sensation and have had normal and regular bowel evacuations without or with occasional soiling. We hope that this procedure may help to improve the functional results in this serious malformation.
REFERENCES

Babcock, W. W. (1947). Radical single stage extirpation for cancer of the large bowel, with retained functional anus. Surg. Gynec. Obstet., 85. 1.

Bacon, H. E. (1949). Cancer of the rectum. Surgery, 46, 584 and Ross, S. T. (1954). Atlas of Operative Technic: Anus, Rectum and Colon. C. V. Mosby, St. Louis.

Brayton, D. and Norris, W. J. (1958). Further experiences with the treatment of imperforate anus. Surg. Gynec. Obstet., $107,719$.

Browne, D. (1955). Congenital deformities of the anus and the rectum. Arch. Dis. Childh., 30, 42.

Bruch, H. (1955). Sexualstörungen nach Radikaloperationen am Mastdarm. Bruns' Beitr. klin. Chir., 190, 418.

Devine, H. E. and Webb, E. E. (1951). Cited by Hartl (1960).

Forshall, I. (1957). Ano-rectal abnormalities. Brit. J. clin. Pract., 11, 842.

Gross, R. E. (1959). Discussion to Scott and Swenson. Ann. Surg. $150,486$.

Hartl, H. (1960). Zur Operation der hohen Anal- und Rectumatresie. Wien. med. Wschr., 110, 516.

Hecker, W. C. (1961). Zur Chirurgie der Anal- und Rectumatresie mit Fistelbildung. Chir. Praxis. Heft 3, p. 383.

Ladd, W. E. and Gross, R. E. (1934). Congenital malformations of anus and rectum. Report of 162 cases. Amer. J. Surg., 23, 167.

Macleod, N. (1880). Case of imperforate rectum, with a suggestion for a new method of treatment. Brit. med. J., 2, 657 .

Norris, W. J., Brophy, T. W. and Brayton, D. (1949). Imperforate anus. A case series and preliminary report on the one stage anus. A case series and preliminary

Potts, W. (1959). The Surgeon and the Child. Saunders, Philadelphia.

Potts, W. J., Riker, W. L. and DeBoer, A. (1954). Imperforate anus with recto-vesical, -urethral, -vaginal and -perineal fistula. Ann. Surg., 140, 381.

Ravitch, M. M. (1948). Anal ileostomy with sphincter preservation in patients requiring total colectomy for benign conditions. Surgery, 24, 170

- and Handelsman, J. C. (1951). One stage resection of entire colon and rectum for ulcerative colitis and polypoid adenocolon and rectum for ulcerative colitis
matosis. Bull. Johns Hopk. Hosp., 88, 59.

Rehbein, F. (1959). Operation der Anal- und Rectumatresie mit Recto-Urethra!fistel. Chirurg, 30, 417

Rhoads, J. E., Pipes, R. L. and Randall, J. P. (1948). A simultaneous abdominal and perineal approach in operations for imperforate anus with atresia of the rectum and rectosigmoid. Ann. Surg., 127,552 .

Romualdi, P (1960). Eine neue Operationstechnik für die Behandlung einiger Rectummissbildungen. Langenbecks Arch. klin. lung einiger $\mathrm{R}$ Chir., 296, 371.

(1961). Treatment of some particularly difficult cases of anus prostaticus. Riv. Chir. pediat., 3, 27.

Scott. J. E. S. and Swenson, O. (1959). Imperforate anus. Results in 63 cases and some anatomic considerations. Ann. Surg., $150,477$.

Snyder, W. H., Jr. (1961). Imperforate anus. Amer. J. Surg., 101, 633 .

Stelzner, F. (1957). Das Problem der Kontinenz bei ano-rectalen Eingriffen. Chirurg, 28, 155. 